\title{
The progression of the boreal winter monsoon through the western Maritime Continent as differentiated by ENSO phase
}

\author{
Shao-Yi Lee and John L. McBride \\ Meteorological Service Singapore, Singapore \\ Correspondence to: Shao-Yi Lee (s13leesy@gmail.com)
}

Received: 11 December 2015 - Revised: 9 August 2016 - Accepted: 13 August 2016 - Published: 24 August 2016

\begin{abstract}
The impact of global ENSO on the regional monsoon onset over the Maritime Continent is examined, using satellite-derived scatterometer surface winds over the sea channel from the South China Sea, through the Karimata Strait into the Java Sea. An index of monsoon onset, fracsign, is defined based on a positive dot-product between the monthly wind at each gridpoint and the "basis-wind" or climatological wind at the peak of the relevant monsoon season.

Rather than being delayed throughout the Maritime Continent during El Niño years, the monsoon is seen to arrive faster at and remain longer over the western Maritime Continent, and therefore delayed for the eastern Maritime Continent. The wind-based diagnostic can be further decomposed into two components that reflect the monsoon wind strength and the location of the wind convergence zone, respectively. During El Niño years, the monsoon strength post-onset is weaker than normal over the eastern maritime continent. However, there is no ENSO-related differentiation in monsoon strength post-onset over the western Maritime Continent.
\end{abstract}

\section{Introduction}

An important regional process in the context of global ENSO is its impact on monsoon onset over the Maritime Continent (see Chang et al. (2004) and Robertson et al. (2011) for comprehensive reviews of the Maritime Continent monsoon). Weather forecasters in the Maritime Continent countries of Malaysia, Indonesia and Singapore base their daily forecasts and weekly outlooks on the seasonal progression of the monsoon wind systems: the northwest and southeast monsoons south of the equator; and their equivalents north of the equator (southwest and northeast monsoons). This pa- per addresses the onset of the monsoon during the seasonal transition from northern summer to southern summer, utilising the sea state scatterometer winds to develop a means of monitoring this transition.

By definition, the monsoon wind systems have a reversal in direction from summer to winter. In this paper a monsoon onset index, fracsign, is defined in terms of the transition of the surface winds to with $90^{\circ}$ of the peak direction. It will be shown the progression through the South China Sea (north of the equator) and into the Java Sea (south of the equator) has a different character in El Niño years to that in La Niña years.

Since the colonial era it has been known that over the Maritime Continent El Niño is associated with dry conditions (see Nicholls (1981) for a review of the historical literature). Years corresponding to large-scale high pressure over Indonesia (now known as El Niño years) are associated with much drier than normal dry seasons, and a late arrival of the austral summer (or boreal winter) wet season in Indonesia (e.g. Braak, 1919; Reesinck, 1952; Hamada, 2002). However, over the western side of the Maritime Continent ENSO has a weak influence on boreal winter precipitation (Aldrian and Susanto, 2003; Chang et al., 2004). As shown by McBride et al. (2003), Chang et al. (2003) and Tangang and Juneng (2004) there is a strong regional structure in the response of rainfall to ENSO at this time of year, with geographically near regions showing opposite sign of the response.

Such regional differences have been attributed to various physical mechanisms, including change in sign of wind feedback on surface fluxes proposed by Nicholls (1981) and Hendon (2003); similar mechanisms but through cloud radiation feedback (Hackert and Hastenrath, 1986); stronger and weaker amplitudes of an ENSO-associated "boomerang" 
SSTA over winter and summer hemispheres, resulting in stronger and weaker ENSO influence respectively (McBride et al., 2003); SSTA driving a cyclonic anomaly over the South China Sea, creating moisture convergence or divergence over regions of high or low ENSO-influence respectively (Tangang and Juneng, 2004; Juneng and Tangang, 2005). Sumatra terrain may isolate the western Maritime Continent from Indian Ocean's ENSO-associated influence while the Pacific-side influences are relatively distant (Chang et al., 2003). Furthermore, the change in the strength and sign of the ENSO-rainfall relationship is tied to different multiscale dynamical processes operating before and after monsoon onset (Moron et al., 2009; Qian et al., 2010).

The onset of the boreal winter monsoon is gradual as monsoon convection travels along the Maritime Continent land bridge during the months of September to February (Lau and Chan, 1983; Tanaka, 1994). Seasonal precipitation follows in general, but the characteristics of the annual cycle at different locations in the Maritime Continent can be strongly affected by orography, so the wet season over certain regions can be during boreal spring, fall, summer, or even multiple seasons (Chang et al., 2005). This creates some difficulty in determining the status of the monsoon over the western Maritime Continent based on precipitation alone (e.g. Wang and LinHo, 2002).

Another meteorological variable commonly used to calculate monsoon indices is wind (e.g. Troup, 1961; Drosdowsky, 1996; Lu and Chan, 1999; Li and Zeng, 2002; Webster and Yang, 1992; Nguyen et al., 2014). In this study, a wind-based diagnostic for onset is defined and used to document the progression of the monsoon through the western Maritime Continent, as differentiated by ENSO phases. The study focuses on describing the monsoon progression over the sea regions of the western Maritime Continent and particularly the South China Sea, to utilise the sea state scatterometer data set, and to complement the results of previous studies.

\section{Data and Methodology}

\subsection{Data source for wind and ENSO phase}

Sea-state-scatterometer surface wind was taken from the Cross-Calibrated Multi-Platform (CCMP) Ocean Surface Wind Vector Analyses (Atlas et al., 2011). The period covered by the data is 1988 to 2011. The scatterometer wind is not available over land and shallow seas. Over sea regions, the results in this manuscript have compared well with that results from the $10 \mathrm{~m}$ wind from the European Centre for Medium-range Weather Forecasts (ECMWF) Interim Reanalysis (not shown). However, only the scatterometer results are shown in this manuscript so that the plots are as observationally-based as possible. This is particularly because of the archipelagic nature of the western Maritime Continent, which may see resolution-caused inaccuracies in the reanalysis winds.
ENSO phase was determined using the Oceanic Niño Index (ONI) from the Climate Prediction Center of the United States National Oceanic and Atmospheric Administration (CPC/NOAA). A year was selected to be an El Niño year when the ONI was greater than 0.5 from September to February of the following year. Since the study aims to track wind convergence throughout the October-February period, the thresholds were applied from September, to ensure Niño conditions were already established by October. Similarly, the year was selected to be Niña for ONI less than -0.5 .

\subsection{Definition of the "fracsign"}

The gradual spatial onset of the boreal winter monsoon, as well as its temporal variability of active and break periods make it difficult to determine the exact onset date at any given location. This study only determines how far the monsoon has progressed in the monthly mean. The "fracsign" at any location is defined as:

$F S \equiv \frac{\boldsymbol{u} \cdot \boldsymbol{u}_{0}}{\boldsymbol{u}_{0} \cdot \boldsymbol{u}_{0}}$

The symbol $\boldsymbol{u}$ denotes to the monthly mean wind, while $\boldsymbol{u}_{0}$ denotes the basis wind of the monsoon season. Monsoon onset is defined to have occurred - in the monthly mean sense - when the fracsign changes from negative to positive value, i.e. the monthly mean wind direction has rotated to within $90^{\circ}$ of the basis wind direction. The basis wind is intended to be the wind during the peak of the monsoon, representing the direction and strength of the wind when the monsoon has been fully established (see details next paragraph). Therefore, the dot product of the monthly mean wind with the basis wind, or the projection of the monthly mean wind onto the basis wind, represents the strength of the monthly mean wind in the "correct" monsoon direction.

A feature of fracsign as a monsoon index is that the definition varies from gridpoint to gridpoint across the domain, depending on the direction and magnitude of the basis wind at each gridpoint. Thus it is designed to take into account the spatial structure of the monsoon wind system.

The basis wind of a monsoon season is defined here as the climatological mean wind of the month with the maximum magnitude in that season (Fig. 1). Annual cycles of wind magnitude over the Asian monsoon region provide a natural partition of the year into two periods of October-March and April-September, corresponding to winter and summer monsoons inclusive of adjoining inter-monsoon months. The transition from one monsoon season to the other is accompanied by a change in wind direction, with wind coming more frequently from one direction than the opposite or nearly opposite direction. As the peak of monsoon season approaches, the wind direction becomes more consistent and the magnitude of the mean wind increases to a maximum. In locations where there is only one maximum magnitude in the annual cycle of the climatological mean wind, the wind six months 


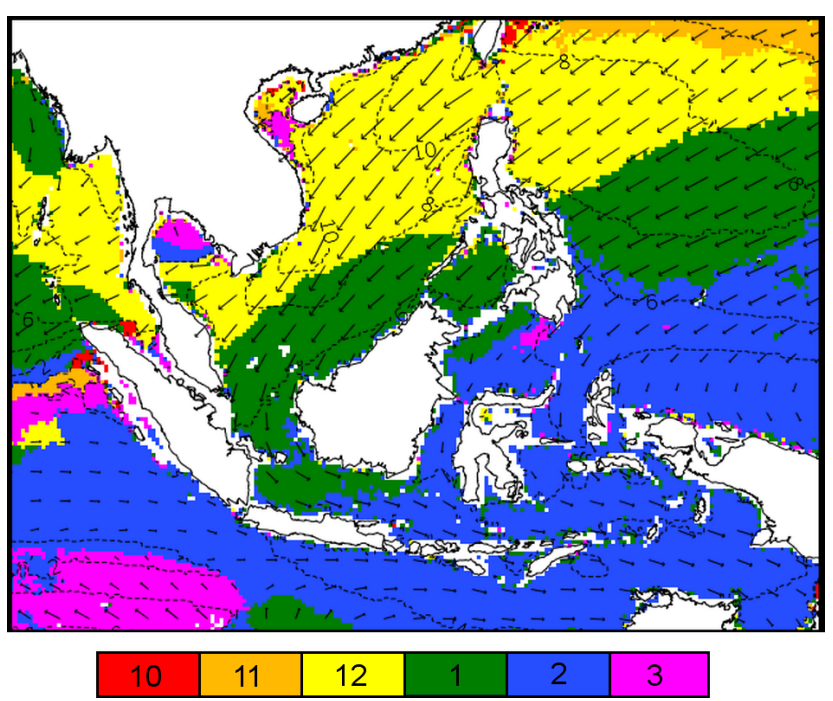

Figure 1. Basis wind for fracsign calculation. Dotted contours show the wind magnitude while arrows indicate direction. Colours show the month when the maximum wind magnitude occurs.

away from the month of that single maximum is used as the basis wind of the other season.

\subsection{Decomposition of fracsign}

The fracsign can be written as

Fracsign $=F S=\frac{|\boldsymbol{u}|}{\left|\boldsymbol{u}_{0}\right|}\left(\hat{\boldsymbol{u}} \cdot \hat{\boldsymbol{u}}_{0}\right)$

with $F=\frac{|\boldsymbol{u}|}{\left|\boldsymbol{u}_{0}\right|}$ and $S=\left(\hat{\boldsymbol{u}} \cdot \hat{\boldsymbol{u}}_{0}\right)$, where $\hat{\boldsymbol{u}}$ and $\hat{\boldsymbol{u}}_{0}$ are unit vectors in the direction of $\boldsymbol{u}$ and $\boldsymbol{u}_{0}$ respectively. Thus, the fracsign is product of the monthly mean wind speed as a fraction of the basis wind speed $(F)$, and the projection of the monthly mean wind direction onto the direction of the basis wind $(S) . F$ then represents the monthly mean wind magnitude compared to the expected monsoon wind magnitude, regardless of direction. $S$ contains the directional information, representing how well-aligned the monthly mean wind is with the expected monsoon wind direction

\subsection{Composites}

Composites of La Niña, phase-neutral and El Niño years were created by averaging positive values of fracsign over La Niña, phase-neutral and El Niño years. Thus, regions with values of zero are pre-onset regions in all years. Regions with values increasing to one in the composite have experienced onset in an increasing number of years. If negative values were included in the average, it would more difficult to determine pre-onset regions since addition of positive and negative values could result in a range of positive and negative values.

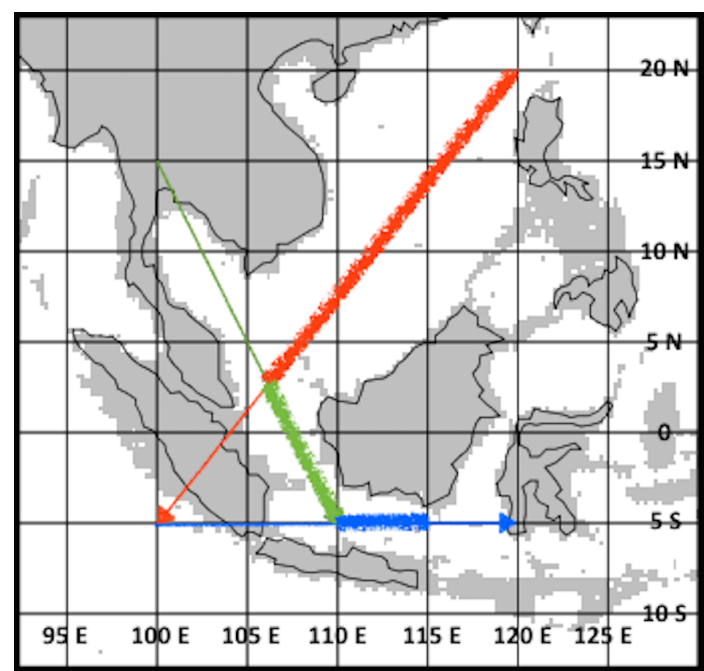

Figure 2. The paths along which cross-sections were taken.

\subsection{Cross-sections}

Cross-sectional values of fracsign $F S, F$ and $S$ were taken along the sections $\mathrm{A}$ to $\mathrm{C}$ as shown in Fig. 2. At each point of the path, the mean was taken of surrounding values of up to $2^{\circ}$, i.e. of the surrounding 8 grids. The averaging provides a representative value of the diagnostic along the path but includes values to still lie within the sea channel, since coastal values may suffer from retrieval inaccuracies caused by shallow water. For paths A and B, values were plotted by latitude. For path $\mathrm{C}$, values were plotted by longitude.

To check whether the Niño and Niña populations were significantly separated, averages of the three diagnostics were taken for each year along latitudes $12-6^{\circ} \mathrm{N}$ (Section A), latitudes $3^{\circ} \mathrm{N}-3^{\circ} \mathrm{S}$ (Section B), and longitudes $108-114^{\circ} \mathrm{E}$ (Section C). A one-tail $t$ test was performed at significance level $5 \%$ with the null hypothesis of no difference between the population mean of Niño and Niña years. Note that a statistically significant difference may still be a small difference and not too meaningful (e.g. Fig. 8e), thus readers are advised to take into account the actual values of the diagnostics as well. However, finding a significant difference with such small samples means the populations are well separated, as can be seen by eye on the relevant figures.

\section{Results}

Using the definitions described in Sect. 2.1, the data period of 1988-2011 was divided into seven El Niño years, nine La Niña years, and seven phase-neutral years. The El Niño years consist of years 1991, 1994, 1997, 2002, 2004, 2006 and 2009. The La Niña years consist of 1988, 1995, 1998, 1999, 2000, 2005, 2007, 2008, 2010. The years 1989, 1990, 1992, 1993, 1996, 2001, 2003 were considered phased-neutral. 

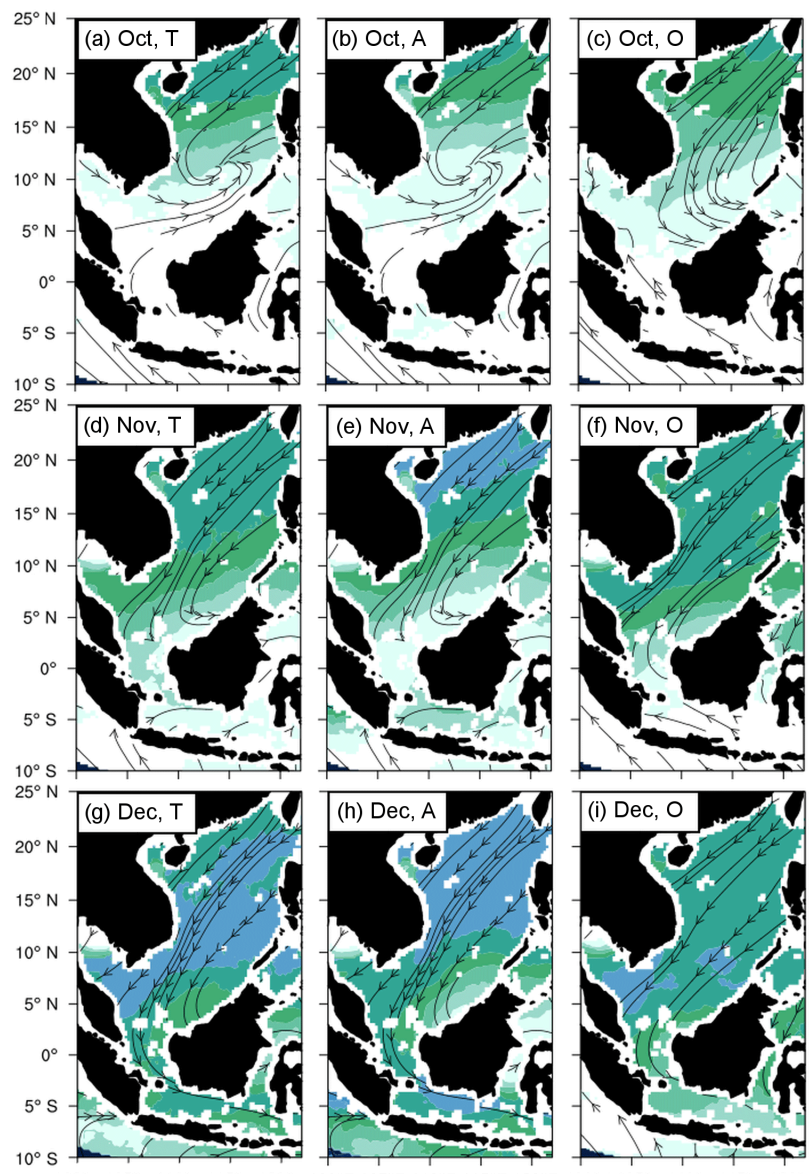

$100^{\circ} \mathrm{E} 105^{\circ} \mathrm{E} 110^{\circ} \mathrm{E} 115^{\circ} \mathrm{E} 120^{\circ} \mathrm{E} 100^{\circ} \mathrm{E} 105^{\circ} \mathrm{E} 110^{\circ} \mathrm{E} 115^{\circ} \mathrm{E} 120^{\circ} \mathrm{E} 100^{\circ} \mathrm{E} 105^{\circ} \mathrm{E} 110^{\circ} \mathrm{E} 115^{\circ} \mathrm{E} 120^{\circ} \mathrm{E}$

$$
\begin{array}{llllllllll}
0 & 0.2 & 0.4 & 0.6 & 0.8 & 1 & 1.2 & 1.4 & 1.6 & 1.8
\end{array}
$$

Figure 3. Composites of fracsign calculated from monthly mean wind. (a-c) For the month of October, for (a) phase-neuTral years, (b) La Niña years, and (c) El NiñO years. Shades show the composited value of fracsign, while arrows show streamlines for wind direction (d-f) as above but for November. (g-i) as above but for December.

Returning to Fig. 1, It is seen by inspection that the peak of the monsoon current occurs in the North-easterlies during December across the northern section of the South China Sea. In the western and southern sections, the wind magnitude also peaks during the boreal winter (northeast) monsoon, but occurs in January. South of the Equator, the peak flow occurs during the austral summer (northwest) monsoon, in the month of February.

\subsection{Composites}

Monsoon progression over the South China Sea and western Maritime Continent differs between El Niño and La Niña years. This is seen in Figs. 3 and 4, where white and the lightest green shade represent regions before and just at monsoon onset, respectively. Note that coastal areas are always white

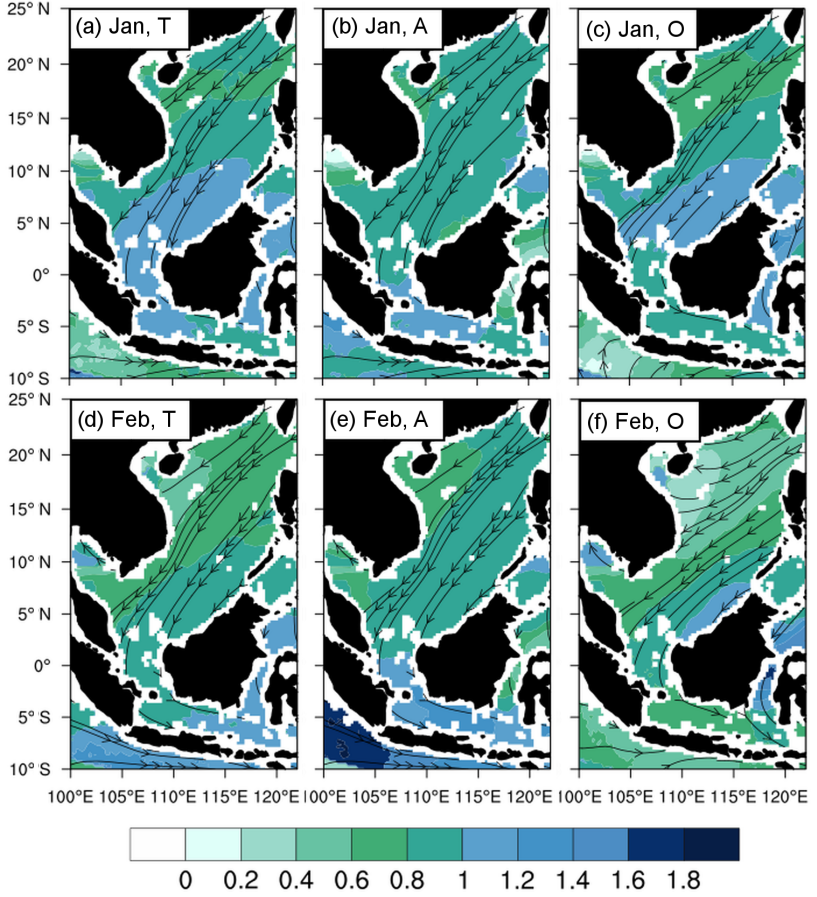

Figure 4. Like Fig. 3 but for (a-c) January, and (d-f) February.

as the study is based on satellite-remotely-sensed ocean surface wind data. In October, the monsoon has advanced further south during El Niño years than during La Niña years (Fig. 3c vs. b). However, the situation is reversed by December, with the monsoon during La Niña years leading that during El Niño years (Fig. 3h vs. i).

Running 3-pentad composites through the months of October and November show the transition between Niño-forward and Niña-forward (Fig. 5). Geometrically, surface convergence occurs at the head of the region of low values of fracsign in the panels. During El Niño years, the initial southward progression of the monsoon is faster than usual over the South China Sea, but surface wind convergence remains over the equator for a month (Fig. $5 \mathrm{q}-\mathrm{x}$ ). During La Niña years, wind convergence quickly crosses or even skips over the equator (Fig. 5i-p). In contrast to the phaseextreme years, during phase-neutral years the northerly monsoon winds gradually move through the South China Sea and the sea passage into Indonesia (Fig. 5a-h).

By February, the monsoon is established over the Maritime Continent domain (Fig. 4). During El Niño years, monsoon winds are indeed weaker than usual south of the equator, but this is not the case north of the equator (Fig. $4 \mathrm{f}$ vs. d). Conversely, during La Niña years, monsoon winds are weaker north of the equator and stronger south of the equator (Fig. 4e vs. d). Monsoon winds from the South China Sea turn from easterly to westerly as they cross the equator, while ENSO equatorial wind anomalies remain unidirectional for any particular phase, thus strengthening or hindering the 


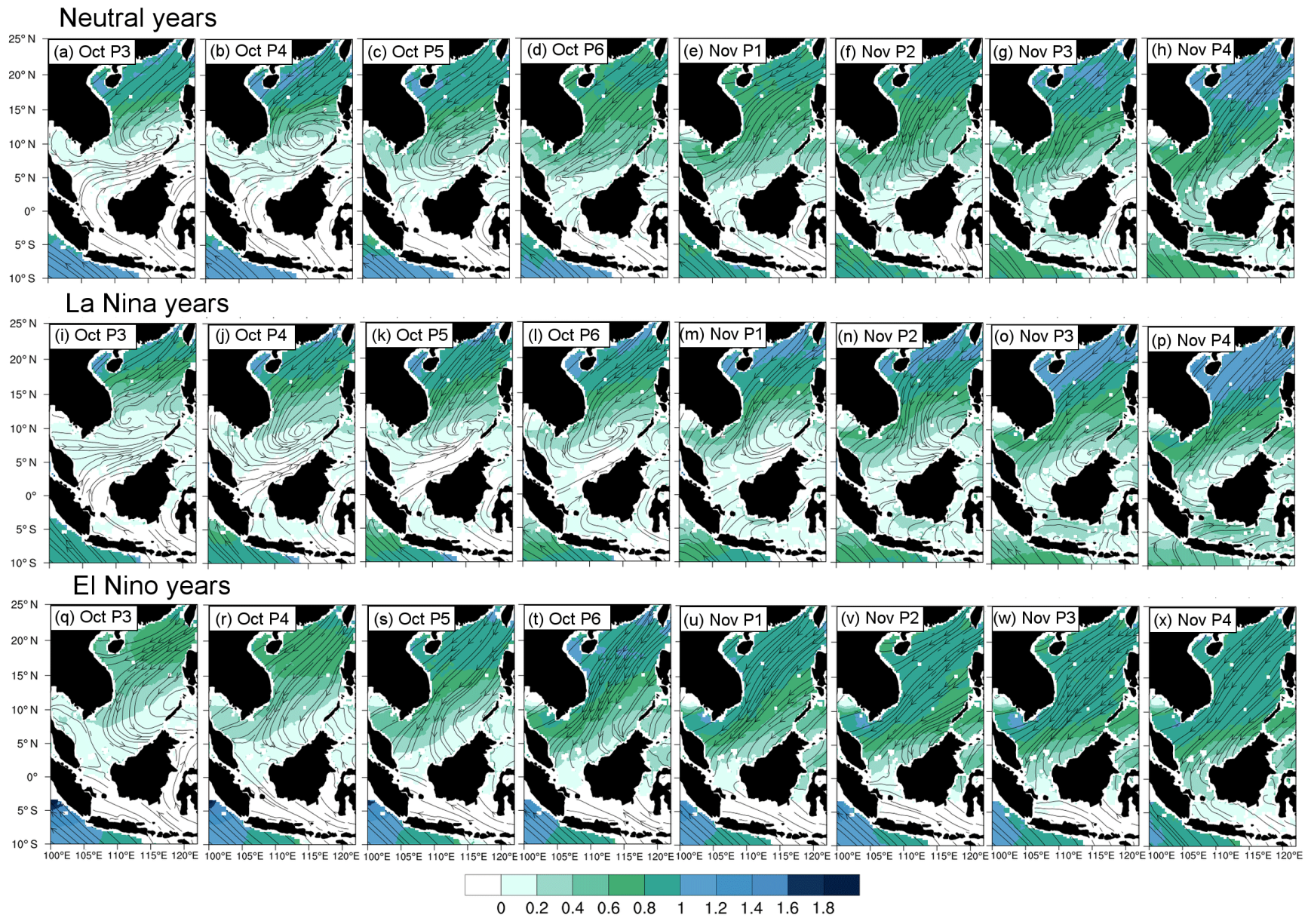

Figure 5. Like Fig. 3, but calculated from running 3-pentad mean wind, during October and November. The label indicates the central pentad. (a-h) phase-neutral years, (i-p) La Niña years, (q-x) El Niño years.

turning monsoon winds. However, this does not explain the lingering of the convergence zone at the equator during El Niño years; if it were purely a matter of summing up gradually changing prevailing winds such as in the phase-neutral situation with ENSO-induced wind anomalies, the movement would be gradual.

\subsection{Cross-sections}

To see the distribution of fracsign for individual ENSO years, cross-sections were taken along paths $\mathrm{A}, \mathrm{B}$ and $\mathrm{C}$ which cover the South China Sea, the Karimata Straits and the Java Sea respectively (Figs. 6-8). The thin grey, blue and red lines are cross-sections for phase-neutral, La Niña and El Niño years, respectively. Thick black, blue and red lines plot the mean values. The thin grey lines for phase-neutral years were de-emphasized on purpose so as not to clutter up the fracsign distribution of La Niña and El Niño years. Red and blue asterisks next to the path labels indicate cases where the population means are significantly different according to the one- sided $t$ test. Blue (red) is for the case where the La Niña (El Niño) mean is greater

During October and November, the El Niño fracsign population is largely separated from the La Niña population in regions where the monsoon has reached (Fig. 6a and b). Note that the extents along the paths where values lie above zero reflect the progression of the monsoon. The Niño-forward situation during October is seen from how the red mean line has extended into path $\mathrm{B}$, whereas the black and blue mean lines have not. This is largely due to the effect of a few strong El Niño years. The Niña-forward situation during November is seen from how the blue mean line has extended into path C. This effect is more consistent in that most La Niña years show this behaviour, while only one El Niño year crossed into path $\mathrm{C}$ and did not pass $108^{\circ} \mathrm{E}$. Over the South China Sea, fracsign remains higher during El Niño compared to during La Niña years.

In December, the monsoon has penetrated to the end of path C for all ENSO phases (Fig. 6c). There is no clear differentiation by phase over the path A (South China Sea), but El Niño and La Niña populations are separate over path C, 

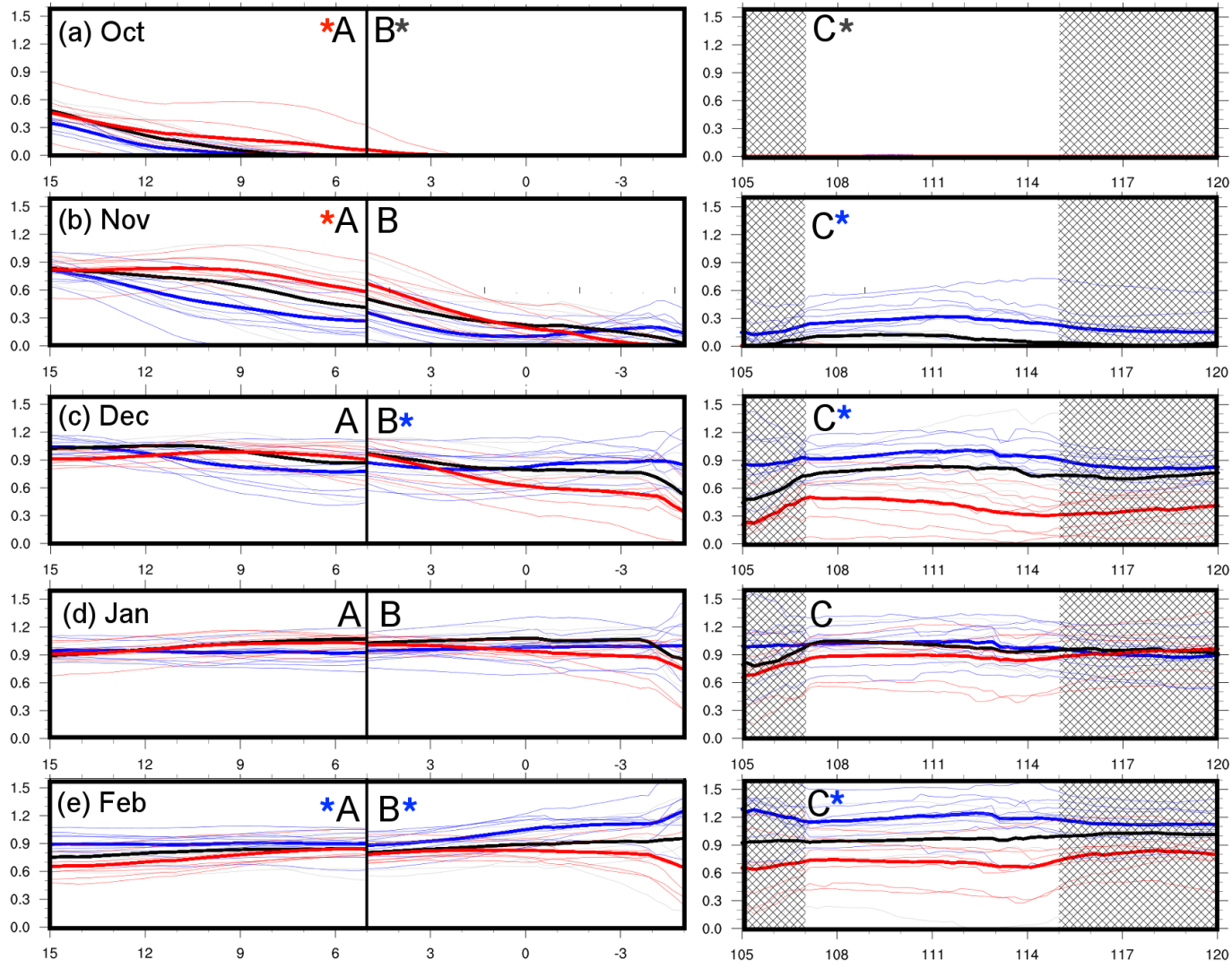

Figure 6. Fracsign calculated along the paths shown in Fig. 2 for (a-e) October to February. Values along path A and B are plotted against latitude $\left({ }^{\circ} \mathrm{N}\right)$, while values along path $\mathrm{C}$ are plotted against longitude $\left({ }^{\circ} \mathrm{E}\right)$. Thin grey, blue and red lines show values for individual phaseneutral, La Niña and El Niño years. Thick black, blue and red lines show mean values for the three phases. Red or blue asterisks next to the path label indicate whether the Niño or Niña values were significantly greater than the other (see Sect. 2.5), grey asterisks indicate testing was not done while no asterisks indicate the null hypothesis was not rejected.

with fracsign being much lower in El Niño years. As with December, during January and February there is no differentiation by phase over path $\mathrm{A}$, as well as over the northern hemispheric section of path B (Fig. 6d and e). Over path C, the separation weakens in January but reappears in February.

While it will be informative and important whether the results differed for Modoki or central Pacific El Niño events (e.g. Ashok et al., 2007; Kao and Yu, 2009), such a detailed analysis will be beyond the scope of the current study. However, based on the El Niño Modoki Index (EMI) proposed by Ashok et al. (2007) as a Modoki measure, two of the events here $(1997,2006)$ were very clear eastern Pacific or canonical events. By visual inspection values of fracsign do not show obvious differences for these years from the other El Niño events. Due to the size of the samples, it is inconclusive whether there are any differences in fracsign between different subsets of Niño events.

The differences in fracsign $F S$ can be attributed to $F$ (frac) reflecting monsoon wind magnitude, or $S$ (sign) reflecting wind direction, respectively. During October, $F$ not strongly phase-differentiated over the South China Sea, except for one unusual El Niño year (Fig. 7a, path A). The stronger reason for phase-differentiation in fracsign is $S$, which indicates how far along the paths that winds have aligned themselves with the direction of the monsoon basis wind. In contrast, during January and February, $S$ is almost 1 along the three paths, indicating the establishment of monsoon winds in the direction of the basis winds (Fig. 8d and e). Phasedifferentiation is due to differences in $F$, and populations are only clearly separated along Path $\mathrm{C}$ and along the southern hemisphere of path B (Fig. 7d and e).

\section{Conclusions}

As documented in many studies (Nicholls, 1981; Haylock and McBride, 2001 and others referenced in Sect. 1), El Niño is generally associated with dry conditions over the Maritime Continent. Thus, the observed early onset in the South China Sea during El Niño years seems counter-intuitive. This oddity has also been previously noted by Reid et al. (2012) (see item \#3 in their Summary and Conclusions). 

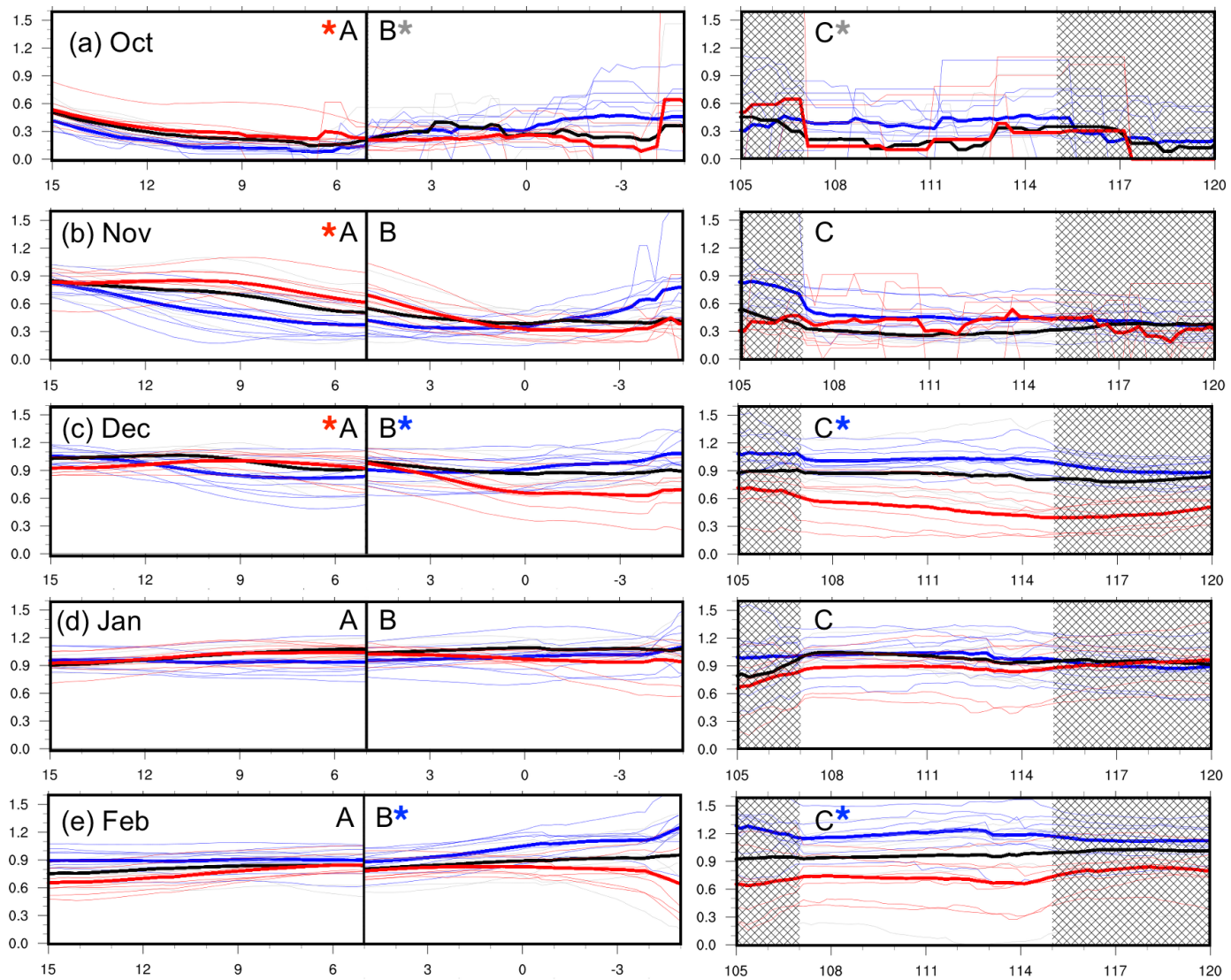

Figure 7. Like Fig. 6 but for the "frac" component, which reflects monsoon wind strength.

The boreal winter monsoon wind is constrained by regional mountain ranges to turn from easterly to westerly as it passes the equator, while ENSO-induced equatorial wind anomalies are unidirectional. In this sense the abovedescribed phenomenon could be considered a regional monsoon peculiarity. At the same time, wind turning is inherent in meridional flow, thus without sufficient frictional torque the strong cross-equatorial monsoon flow would arguably not even exist. In this sense, such hemispheric differences could be considered inherent in monsoons. It would be interesting to see whether such behaviour is typical for other monsoonal regions, particularly the lingering of the convergence zone at the equator.

Finally, while the ENSO phase-differentiation in boreal winter monsoon progression is quite apparent, the authors have found that phase-differentiation of the quantity of mean monsoon precipitation over the western Maritime Continent is not obvious. Thus usual drought prediction during El Niño years does not extend to this region and season, although it has been previously noted that El Niño-associated drought effects is seen in boreal summer rainfall (e.g. Kirono et al., 1999). That ENSO phase-differentiation of boreal winter monsoon precipitation is weak over the region is reflected in the difficulty that some forecast models have in replicating observed ENSO rainfall teleconnections there (e.g. Aldrian et al., 2003). Diagnostics based on other meteorological variables, such as this wind-based onset diagnostic, may be useful in tracing the source of this uneven model performance when phase differentiation is not seen in rainfall.

It has been noted that the influence of ENSO on the boreal winter precipitation is likely through its modulation on phenomena such as the Madden Julian Oscillation (Wheeler and McBride, 2011), equatorially-trapped waves (Wheeler and McBride, 2011), cold surges (Zhang et al., 1997; Chen, 2004) and their associated vortices (Koseki et al., 2013; Chen et al., 2015), the diurnal cycle (Qian et al., 2010), or active-break cycles (Moron et al., 2015). Thus, the ENSOinfluenced movement of the convergence zone during the monsoon onset period may only indirectly influence western Maritime Continent precipitation through weather-scale events (e.g. Chen et al., 2015). In addition, the western Maritime Continent is located at the region of strongest interannual variability in Indian Ocean sea surface temperature, associated with the eastern branch of the Indian Ocean Dipole IOD (Saji et al., 1999). Thus influences from both the Pacific and Indian Oceans may be important in the monsoon transition of the convergence zone (e.g. Tangang et al., 2008). 

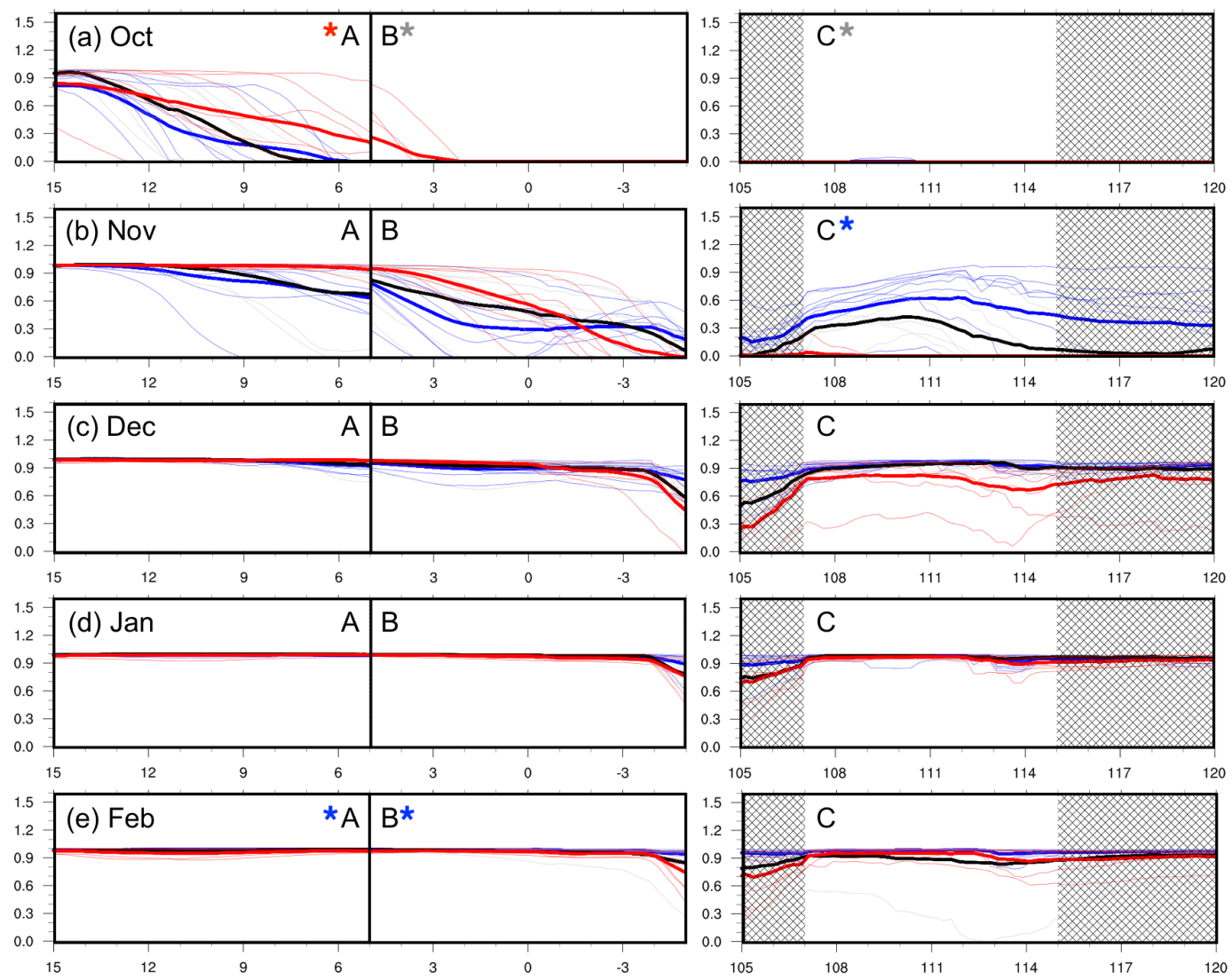

Figure 8. Like Fig. 6 but for the "sign" component, which reflects monsoon wind direction.

As a final comment, we summarise that this paper has presented two new findings:

a. it defined fracsign as an index of the presence of the monsoon circulation that peaks in the Austral summer. It showed that, based on this index the monsoon onset can be traced as occurring progressively through the South China Sea, the Karimata Straits and the Java Sea from October through February.

b. Using the concept that the region between pre-monsoon and established monsoon is a region of monsoon convergence, monsoon convergence was found to arrive at the western Maritime Continent earlier, and remain there longer, during El Niño compared to La Niña years. During El Niño, convergence remained near the equator for over a month before crossing into the southern hemisphere. During El Niño years, monsoon wind strength is stronger and weaker than usual in the sea channel $10^{\circ}$ north and south of the equator, respectively, while the opposite is true for La Niña years. A remarkable aspect of this analysis is the very clear separation between the two families of events (El Niño, La Niña) over certain parts of the domain. This can be seen in the early season in the South China Sea in October-November (section
A in Fig. 6) and in the Java Sea in February (Section C in Fig. 6).

\section{Data availability}

Cross-Calibrated Multi-Platform ocean surface wind is publicly available from the United States National Aeronautics and Space Administration (https: //podaac.jpl.nasa.gov/Cross-Calibrated_Multi-Platform_

OceanSurfaceWindVectorAnalyses). The Oceanic Niño Index is publicly available from the United States National Oceanic and Atmospheric Administration (http://www.cpc.ncep.noaa.gov/products/analysis_ monitoring/ensostuff/ensoyears.shtml).

Acknowledgements. We wish to thank NASA and NOAA for making their data publicly available, as well as P. Xavier, C. Marzin, C. P. Chang and the two anonymous reviewers for their valuable suggestions and comments.

Edited by: J. D. Pabón-Caicedo

Reviewed by: two anonymous referees 


\section{References}

Aldrian, E. and Susanto, R. D.: Identification of three dominant rainfall regions within Indonesia and their relationship to sea surface temperature, Int. J. Climatol., 23, 1435-1452, 2003.

Aldrian, E., Gates, L. D., and Widodo, F. H.: Variability of Indonesian Rainfall and the Influence of ENSO and Resolution in ECHAM4 simulations and in the Reanalyses, MPI Report 346, 30 pp., available from Max Planck- Institut für Meteorologie, Bundesstr. 55, 20146, Hamburg, Germany, 2003.

Ashok, K., Behera, S. K., Rao, S. A., Weng, H., and Yamagata, T.: El Niño Modoki and its possible teleconnection, J. Geophys.Res., 112, 2156-2202, 2007.

Atlas, R., Hoffman, R. N., Ardizzone, J., Leidner, S. M., Jusem, J. C., Smith, D. K., and Gombos, D.: A cross-calibrated, multiplatform ocean surface wind velocity product for meteorological and oceanographic applications, B. Am. Meteorol. Soc., 92, 157174, 2011.

Braak, C.: Atmospheric variations of short and long duration in the Malay Archipelago, Verhandelingen No. 5, Koninlijk Magnetisch en Meteorologisch Observatorium te Batavia, Batavia, Indonesia, 1919.

Chang C.-P., Wang, Z., Ju, J., and Li, T.: On the relationship between western Maritime Continent rainfall and ENSO during northern winter, J. Climate, 17, 665-672, 2003.

Chang, C.-P., Harr, P., McBride, J. L., and Hsu, H : The maritime continent monsoon, in: East Asian Monsoon, edited by: Chang, C.-P., World Scientific Series of Meteorology of East Asia, World Scientific Publishing, Singapore, ISBN: 978-9814483-13-1, 2004.

Chang, C.-P., Wang, Z., McBride, J. L., and Liu, C. H.: Annual cycle of Maritime Continent rainfall and the asymmetric monsoon transition, J. Climate, 18, 287-301, 2005.

Chen, T. C., Huang, W. R., and Yoon, J.-H.: Interannual variation of the East Asian cold surge activity, J. Climate, 17, 401-413, 2004.

Chen, T. C., Tsay, J.-D., Matsumoto, J., and Alpert, J.: Development and Formation Mechanism of the Southeast Asian Winter Heavy Rainfall Events around the South China Sea. Part I: Formation and Propagation of Cold Surge Vortex, J. Climate, 28, 1417-1443, 2015.

Drosdowsky, W.: Variability of the Australian summer monsoon at Darwin: 1957-1992, J. Climate, 9, 85-96, 1996.

Hackert, E. C. and Hastenrath, S.: Mechanisms of Java rainfall anomalies, Mon. Weather Rev., 114, 747-757, 1986.

Hamada, J. I., Yamanaka, M. D., Matsumoto, J., Fukao, S., Winarso, P. A., and Sribimawati, T.: Spatial and temporal variations of the rainy season over Indonesia and their link to ENSO, J. Meteorol. Soc. Jpn. 80, 285-310, 2002.

Haylock, M. and McBride, J. L.: Spatial coherence and predictability of Indonesian wet season rainfall, J. Climate, 14, 3882-3887, 2001

Hendon, H. H.: Indonesian rainfall variability: Impacts of ENSO and local air-sea interaction, J. Climate, 16, 1775-1790, 2003.

Juneng, L. and Tangang, F. T.: Evolution of ENSO related rainfall anomalies in Southeast Asia region and its relationship with atmosphere-ocean variations in Indo-Pacific sector, Clim. Dynam., 25, 337-350, 2005.

Kao, H.-Y. and Yu, J.-Y.: Contrasting eastern-Pacific and centralPacific types of ENSO, J. Climate, 22, 615-632, 2009.
Kirono, D. G. C., Tapper, N. J., and McBride, J. L.: Documenting Indonesian rainfall in the 1997/1998 El Nino event, Phys. Geogr., 20, 422-435, 1999.

Koseki, S., Koh, T. Y., and Teo, C. K.: Effects of the Cold Tongue in the South China Sea on the Monsoon, Diurnal Cycle and Rainfall in the Maritime Continent, Q. J. Roy. Meteor. Soc., 139, 15661582, 2013.

Lau, K. M. and Chan, P. H.: Short-term climate variability and atmospheric teleconnections from satellite-observed outgoing longwave radiation. Part II: Lagged correlations, J. Atmos. Sci., 40, 2751-2767, 1983.

Li, J. and Zeng, Q.: A unified monsoon index, Geophys. Res. Lett., 29, 115-1-115-4, 2002.

Lu, E. and Chan, J. C.: A unified monsoon index for South China, J. Climate, 12, 2375-2385, 1999.

McBride, J. L., Haylock, M. R., and Nicholls, N.: Relationships between the Maritime Continent heat source and the El NiñoSouthern Oscillation phenomenon, J. Climate, 16, 2905-2914, 2003.

Moron, V., Robertson, A. W., and Boer, R.: Spatial Coherence and Seasonal Predictability of Monsoon Onset over Indonesia, J. Climate, 22, 840-850, 2009.

Moron, V., Robertson, A. W., Qian, J.-H., and Ghil, M.: Weather types across the Maritime Continent: from the diurnal cycle to interannual variations, Front, Environ. Sci., 2, 65, doi:10.3389/fenvs.2014.00065, 2015.

Nicholls, N.: Air-sea interaction and the possibility of longrange weather prediction in the Indonesian Archipelago, Mon. Weather Rev., 109, 2435-2443, 1981.

Nguyen, D. Q., Renwick, J., and McGregor, J.: Variations of monsoon rainfall: A simple unified index, Geophys. Res. Lett., 41, 575-581, 2014.

Qian, J. H., Robertson, A. W., and Moron, V.: Interactions among ENSO, the Monsoon, and Diurnal Cycle in Rainfall Variability over Java, Indonesia, J. Atmos. Sci, 67, 3509-3524, 2010.

Reid, J. S., Xian, P., Hyer, E. J., Flatau, M. K., Ramirez, E. M., Turk, F. J., Sampson, C. R., Zhang, C., Fukada, E. M., and Maloney, E. D.: Multi-scale meteorological conceptual analysis of observed active fire hotspot activity and smoke optical depth in the Maritime Continent, Atmos. Chem. Phys., 12, 2117-2147, doi:10.5194/acp-12-2117-2012, 2012.

Reesinck, J. J. M.: Some remarks on monsoon forecasting for Java, Verhandelingen No. 44, Kementerian Perhubungan Djawatan Meteorologi Dan Geofisik, Jakarta, Indonesia, 1952.

Robertson, A., Moron, V., Qian, J., Chang, C. P., Tangang, F., Aldrian, E., Koh, T. Y., and Juneng, L.: The Maritime Continent Monsoon, 2011, in: The Global Monsoon System: Research and Forecast, 2nd Edn, edited by: Chang, C. P., Ding, Y., Lau, N. C., Johnson, R. H., Wang, B., and Yasunari, T., World Scientific Series on Asia-Pacific Weather and Climate, Vol. 5, World Scientific Publication Company, 608 pp., ISBN 978-981-4343-40-4, 2011.

Saji, N. H., Goswami, B. N., Vinayachandran, P. N., and Yamagata, T: A dipole mode in the tropical Indian Ocean, Nature, 401, 360363, 1999.

Tanaka, M.: The onset and retreat dates of the Austral summer monsoon over Indonesia, Australia and New Guinea, J. Meteorol. Soc. Jpn., 72, 255-267, 1994. 
Tangang, F. T. and Juneng, L.: Mechanisms of Malaysia rainfall anomalies, J. Climate, 17, 3615-3621, 2004.

Tangang, F. T., Juneng, L., Salimun, E., Vinayachandran, P. N., Seng, Y. K., Reason, C. J. C., and Yasunari, T.: On the roles of the northeast cold surge, the Borneo vortex, the Madden-Julian Oscillation, and the Indian Ocean Dipole during the extreme 2006/2007 flood in southern Peninsular Malaysia, Geophys. Res. Lett., 35, LS14S07_1-L14S07_6, 2008.

Troup A. J.: Variations in upper tropospheric flow associated with the onset of the Australian summer monsoon, Indian J. Meteor. Geophys., 12, 217-230, 1961.

United States National Aeronautics and Space Administration: Cross-Calibrated Multi-Platform ocean surface wind, available at: https://podaac.jpl.nasa.gov/Cross-Calibrated_ Multi-Platform_OceanSurfaceWindVectorAnalyses, last access: 19 August 2016.

United States National Oceanic and Atmospheric Administration: The Oceanic Niño Index, available at: http://www.cpc.ncep.noaa. gov/products/analysis_monitoring/ensostuff/ensoyears.shtml, last access: 19 August 2016.
Wang, B. and LinHo: Rainy Season of the Asian-Pacific Summer Monsoon, J. Climate, 15, 386-398, 2002.

Webster, P. J. and Yang, S.: Monsoon and ENSO: Selectively interactive systems, Q. J. Roy. Meteor. Soc., 118, 877-926, 1992.

Wheeler, M. C. and McBride, J. L.: Australasian monsoon, in: Intraseasonal Variability in the Atmosphere-Ocean Climate System (2nd Edn.), edited by: Lau, W. K. M. and Waliser, D. E., Springer, Berlin, Heidelberg, Germany, 147-198, ISBN 978-3-540-272502, 2011.

Zhang, Y. K., Sperber, R., and Boyle, J. S.: Climatology and interannual variations of the East Asian winter monsoon: Results from the 1979-1795 NCEP/NCAR reanalysis, Mon. Weather Rev., 125, 2605-2619, 1997. 